\section{Um livro esquecido: \\ ? "Juiz de Fora"}

\section{Júlio Castañon Guimarães}

Em carta de 10 de novembro de 1926 dirigida a Manuel Bandeira, Mário de Andrade diz: "o que eu quero com interesse que você me escreva é sobre o ponto em que está o caso de você com o Alphonsus" (1). Poucos dias depois, em carta a Carlos Drummond de Andrade, datada de 23 de novembro de 1926, o mesmo Mário de Andrade já dá notícia sobre o assunto: "O caso Manu-Alphonsus resolveu-se da melhor maneira e estou contente. A carta do Alphonsus na Revista do Brasil está bonita e não cai em pieguismo amoroso coisa de que tinha medo devido ao exagero da carta do Manuel"(2). Tanto na edição das cartas de Mário de Andrade a Drummond quanto na das cartas a Bandeira, há notas, referentes aos trechos citados, nas quais é brevemente esclarecido o referido episódio, que envolveu uma pequena rixa e o apreço por um livro de poemas.

No no 2 da Revista do Brasil, de 30 de setembro de 1926, Manuel Bandeira publicou uma nota sobre o livro Juiz de Fora, de Austen Amaro, impresso em Belo Horizonte quatro meses antes, isto , em maio. Dizia, por exemplo, Manuel Bandeira:

\begin{abstract}
"Isto cheira a futurismo do brabo... Há, como essa, muita coisa ruim nesta brochura, estiradas do palavreado sem substância de pensamento ou sensibilidade, um mau gosto horroroso. Apesar de tudo esta poesia é simpática, insinua-se, interessa. Tem ingenuidade e força. Gosto, por exemplo, da vulgaridade jornalística, reclamista do Canto II, onde se esparrama um afeto largo de comoção bem brasileira, sabendo gostosamente ao que os rapazes da Terra Roxa chamam manifestação espontânea de Pau-brasil (...). Todo o canto é de um ridículo sublime e bem haja o poeta que teve a esplêndida coragem desse ridículo. Aquilo é poesia, não tem a menor dúvida"(3).
\end{abstract}

Os comentários podem ser lidos como sendo francamente positivos, mas assim não os leu o escritor mineiro João Alphonsus. Publicou então um artigo no suplemento do jornal $A$ Manhã, em 26 de outubro, defendendo o livro em questão e abertamente irritado com a crítica de Bandeira, a quem julgava um homem bem-posto na vida, que fora injusto com o livro de Austen Amaro. O artigo de João Alphonsus se estende procurando mostrar as qualidades de Juiz de Fora; discutte inclusive sua situação dentro das tendências do modernismo:

"Já se vai tornando banal e ínútil ironizar o passadismo. Também banal e inútil explicar tendências do modernismo. A presença do Brasil na nossa poesia modernista se vem acentuando há muito. Se pode mesmo dizer que a ânsia dos nossos poetas modernos é abrasileirar cada vez mais a poesia. Como? As tentativas vão surgindo"(4)

Estes comentários se fazem logo após o crítico ter-se referido ao livro de Austen

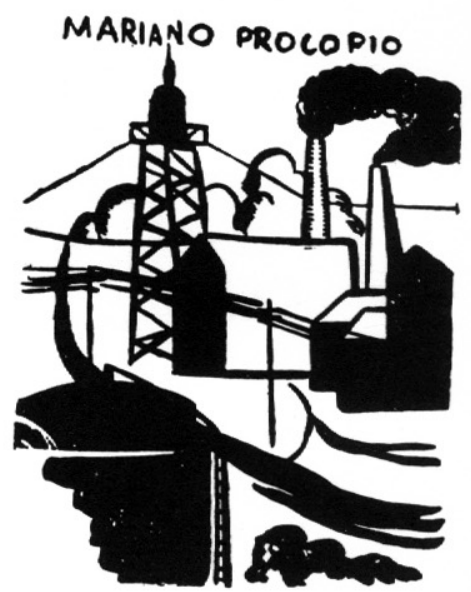

llustração de Pedro Nava para Juiz de Fora
JÚLIO CASTAÑON GUIMARÃES é

pesquisador da Fundação Casa de Rui Barbosa, tradutor e autor de livros sobre Murilo Mendes e Manuel Bandeira (ambos publicados pela Brasiliense).
1 Cartas a Manuel Bandeira, Mário de Andrade. Rio de Janeiro, Ediçסes de Ouro, 1966, p.205.

2 A liçăo do amigo: cartas de Mário de Andrade a Carlos Drummond de Andrade, Mário de Andrade. Rio de Janeiro, José Olympio, 1982, p.95.

3 Andorinha, andorinha, Manuel Bandeira. Rio de Janeiro, José Olympio, 1986, $2^{a}$ ed., p.190. Todos os quatro textos da polêmica foram inclurdos nesse livro de Manuel Bandeira.

4 Id., ibid., p.192. 
À esq., desenho de Pedro Nava para Juiz de Fora; à dir., capa de Nava para o livro
Amaro nos seguintes termos: "Interessante ler um poeta novo contando um Brasil bem diferente da pátria amada, idolatrada! salve! salve! Cantiga forte de brasileirice sem porque-me-ufanismos literários"(5). A partir de certo ponto, porém, João Alphonsus se volta contra Manuel Bandeira, de modo às vezes até ferino:

"Ele sabia que tratava-se de um novo muito mais novo do que ele. Sua atitude se parece com a de certos passadistas que na gata-parida das letras não querem ceder uma beiradinha para os que vêm vindo. (...) Se o poeta Manuel Bandeira gosta de criticar exibindo ruindades, por que deixou passar 'Jorobabel' e outras quando falou de Lasango Cáqui? Losango Cáqui de Mário de Andrade, que aliás muito admiro e estimo. Ora por que! Com Mário o caso é outro. Mostra apenas o que é bom. Tem motivos para elogio puxado. E só elogio. (...) É natural. Austen é moço. Muito moço. Está longe dos 30 e tantos anos que suponho ter o seu crítico. Suponho porque, rapazola em Mariana, lembra-me (me admirem a memória!), ter lido um soneto dele Manuel, no Fon-Fon, cinzento e fúnebre. Retratinho por cima. Comentos por baixo. E a notícia de que o poeta partia como não sei que de legação não sei para onde... Com isso, o poeta do Ritmo Dissoluto não perde a minha admiração. Não está em mim acabar com ela. Mas perdeu a minha simpatia o Dr. Manuel Bandeira, bacharel como toda gente, Manu na intimidade. (...) Se o Manu ler a minha declaração, será decerto com um risinho jemanfichista de quem já fez até versos como quem morre, coitadinho! (Todo mundo tem seus ridículos, grande poeta do 'Berimbau' e dos Sinos de Belém, bem, bem, bem.) Mas é preciso concluir assim de cara fechada o meu artigo. Pronto"(6).

Manuel Bandeira responde com uma "Carta Aberta a João Alphonsus", publicada no no 4 da Revista do Brasil, de 30 de outubro de 1926. Aŕ procura fazer ver que João Alphonsus não compreendera as críticas a Austen Amaro, considerado por Bandeira poeta de qualidades, e que tinha uma idéia equivocada de quem era o homem Bandeira. Nessa carta aberta não é difícil perceber o que Mário de Andrade, ao comentar com Drummond a desavença, considerou como "exagero da carta do Manuel". No plano propriamente pessoal foi este o tom da carta de Bandeira:

"Marquei você desde os tempos em que fui para Campanha escarrando sangue. Foi quando eu escrevia versos 'como quem morre'. Ai de mim, João Alphonsus! tenho mais idade do que você pensa. Já fiz quarenta anos. Ribeiro Couto disse outro dia que eu sou a solteirona do modernismo. Estupendo,
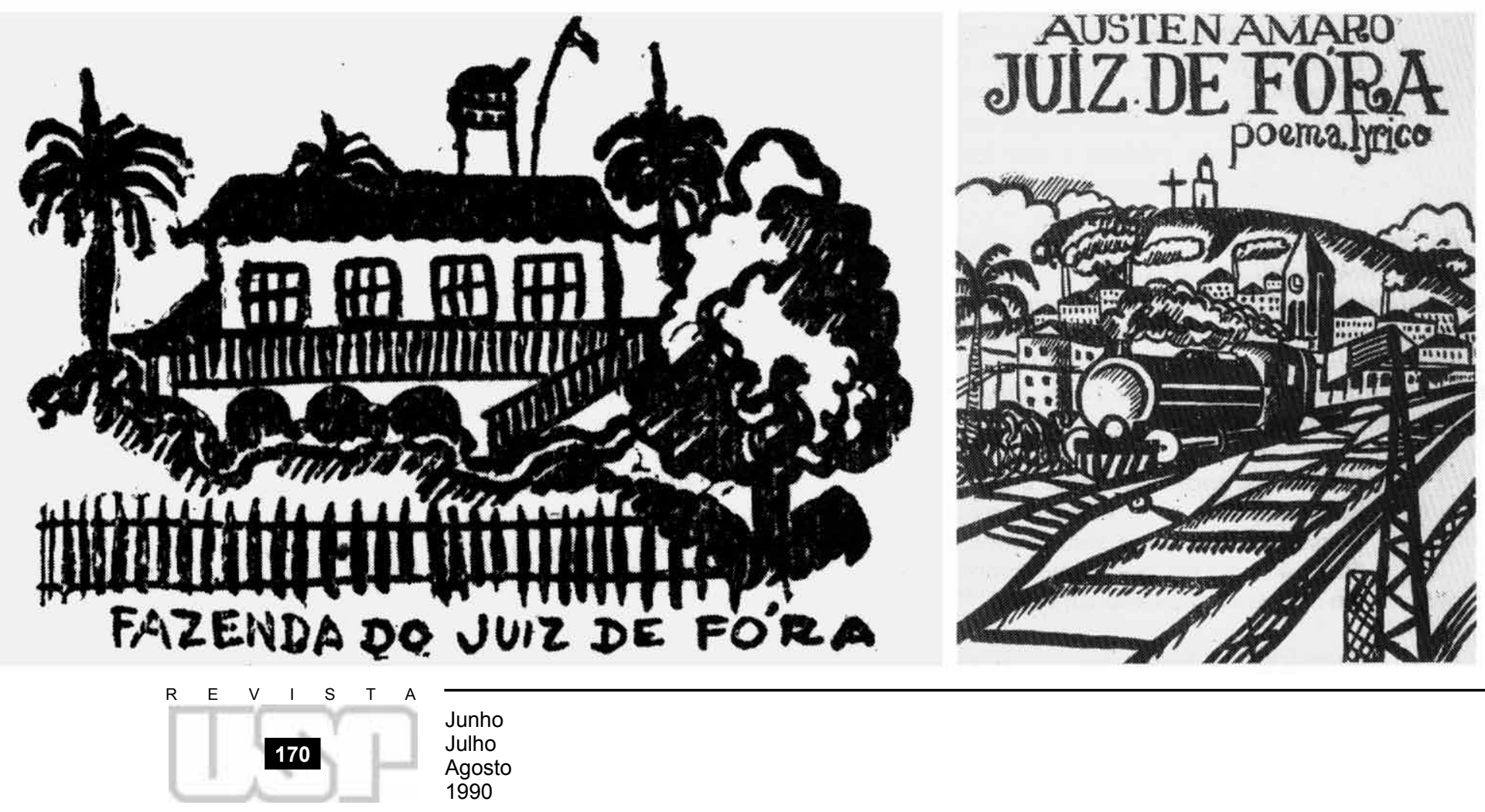
não acha? $O$ pior $€$ que nunca tive mocidade. Entre dezessete e trinta anos eu era muito mais velho do que sou hoje.

Outro engano de sua parte é me tomar por bacharel. Não sou doutor, João Alphonsus, nem nunca parti como não sei de legação pra lugar nenhum. Nunca fui nada em minha vida - senão poeta.

E só fui poeta porque não pude ser outra coisa. É triste, mas é assim, e eu aceito toda a minha tristeza"(7).

Repassando rapidamente as considerações de ambos sobre a poesia de Austen Amaro e Mário de Andrade, Bandeira acaba por declarar: "A verdade é que guardei o poema de Austen Amaro ao lado dos livros de Mário, Guilherme, Ronald, Ribeiro Couto, A. Moreyra, Onestaldo, Olegário, Murilo e outros poetas que prezo"(8). No no seguinte da Revista do Brasil, de 15 de novembro de 1926, João Alphonsus respondia, pondo fim ao incidente. Discutiu mais uma vez a crítica de Bandeira e procurou de novo mostrar as razões de sua defesa do livro de Austen Amaro, encerrando a resposta, desta vez, com uma "Disponha do meu coração".

Além da polêmica que despertou, Juiz de Fora ainda mereceu uma nota que Rosário Fusco assinou com suas iniciais no no 3 da revista mineira Verde, de Cataguases:

\begin{abstract}
"Um poema lírico-moderno cheio de rastros parnasianos e uma bruta influência do Mário.

Acho até que se Austen Amaro não lesse o Noturno de Belo Horizonte não escreveria aquilo. Contudo o livro é moço, vivo, inteligente. E, como em geral acontece: bom e ruim.

Juiz de Fora não é uma coisa definitiva. Austen se quisesse poderia dar pra gente ler coisa muito milhor"(9).
\end{abstract}

Embora tenha provocado tais manifestaçōes, o livro de Austen Amaro praticamente desapareceu. Ficaram as cartas, os artigos, as notas. $O$ livro não apenas não foi reeditado, como também quase não é mencionado. Por exemplo, numa obra de referência especf́fica, a Biografia critica das letras mineiras, de Valtencir Dutra e Fausto Cunha, Austen Amaro é mencionado de passagem. Juiz de Fora tornou-se uma raridade, sendo extremamente difícil localizar um exemplar.

No entanto, em um livro relativamente recente, a obra de Austen Amaro é mencionada de forma enaltecedora. Como a menção $e$ breve e feita em um livro volumoso, que não é obra sobre literatura, mas um livro de memórias, provavelmente não tem despertado muita atenção. Pedro Nava em Beira-mar, quarto volume de suas memórias, fornece uma série de informações sobre Austen Amaro e sua obra, fazendo em especial alguns comentários sobre o livro Juiz de Fora. Em cerca de uma página, o memorialista faz uma exposição sumária mas esclarecedora sobre a poesia de Juiz de Fora. Escreve Pedro Nava:

\begin{abstract}
"Os acasos da vida levaram aquele poeta (Austen Amaro) a Juiz de Fora no ano de 1925 e ele foi literalmente tomado pela vida industrializada e cheia de força do meu munićpio, da minha cidade e escreveu sobre esta um poema que teria o fado de ser o primeiro livro modernista publicado em Minas Gerais. (...) $\mathrm{O}$ poema de Austen Amaro é composto sob a inspiração da Força que ele sentiu em Juiz de Fora, em Minas, no Brasil. Tem de Ronald de Carvalho e de Walt Whitman (...). Sente-se sua impotência de frear a poesia irrompendo tão abundante e tumultuosa que exige novas formas e novas palavras para se configurar"(10).
\end{abstract}

Pedro Nava, no entanto, não foi apenas leitor e contemporâneo de Austen Amaro, de cuja poesia soube apontar certeiramente aspectos capitais. Vale lembrar que o memorialista foi também desenhista (são conhecidas suas ilustraçōes para Macunatma e mereceriam também vir a público os minuciosos desenhos feitos nos originais de seus livros de memórias). E a relação de Pedro Nava com Juiz de Fora se revela mais estreita, quando no trecho em que fala de Austen Amaro faz esta revelação: "Tive a honra de colaborar com três desenhos"(11). A edição de Juiz de Fora efetivamente traz ilustrações de Pedro Nava, fato duas vezes mencionado por Manuel Bandeira. Na nota que escreveu sobre o livro, observa Bandeira rapidamente: "Bons desenhos de Pedro Nava",(12)

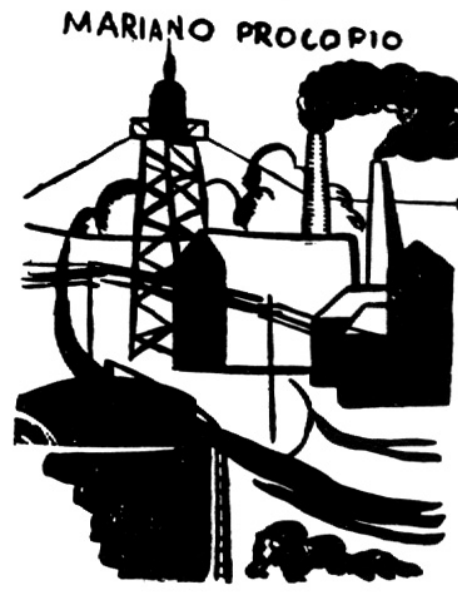

5 ld., ibid., p.192.

6 Id., ibid., pp. 193-194.

7 Id., ibid., p.194. Foi entre 1905 1906 que, tuberculoso, Manuel Bandeira passou um perlodo em Campanha, Minas Gerais, em busca de clima apropriado à sua saúde.

8 Id., ibid., p.195.

9 Verde. Cataguases, ano 1, $n^{9} 4$ p.10.

10 Beira-mar, Pedro Nava. Rio de Janeiro, José Olympio, 1978, pp. 221-222.

11 Id., ibid. p.221.

12 Andorinha, andorinha, Manuel Bandeira. p.191.

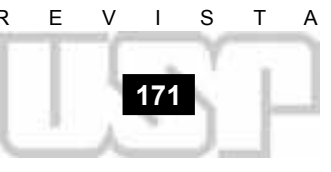


Da esquerda para a direita: fac-símile do trecho inicial da "Introdução" de Juiz de Fora, com palavras sublinhadas por Pedro Nava e correção feita por Austen Amaro; fac-símile do Canto VI, um dos̀ poemas curtos de Juiz de Fora; fac-símile de outro poema curto do livro, com trecho sublinhado por Pedro Nava
Na carta-aberta dirigida a João Alphonsus, ao dizer que guardara o livro de Austen Amaro entre os poetas que prezava, acrescentou: "E lhe garanto que não guardei somente por causa dos excelentes desenhos de Pedro Nava"(13). Rosário Fusco, na nota de Verde, também não deixou escapar o fato: "Desenhos bonitos de Nava sujam os olhos da gente de preto"(14).

Mais do que um elemento histórico circunstancial, o encontro do desenho de Pedro Nava com a poesia de Austen Amaro pode se prestar ainda a esclarecimentos sobre esta última. Assim, ao comentar seus próprios desenhos, Pedro Nava também dá indícios da poesia que ilustrou. Escreveu ele:

"O (desenho) da capa mostra uma perspectiva urbana cheia das chaminés de fábricas e vê-se o Morro do Imperador olhado da estação da Central. O segundo representa o 'longe Mariano Procopi das paralelas'. O terceiro tenta dar uma idéia dos fundos da Fazenda Velha do Tenente Antônio Dias Tostes"(15).

Tem-se assim um livro que - "primeiro livro modernista publicado em Minas Gerais" - surgiu plenamente envolvido com as questões modernistas, não apenas por razões cronológicas, mas por conter elementos próprios do projeto modernista. Hoje, porém, subsiste uma dificuldade elementar: encontrar um exemplar de Juiz de Fora, verdadeira raridade. No Centro de Literatura Brasileira da Fundação Casa de Rui Barbosa, no Rio de Janeiro, há um exemplar. Pertenceu a Pedro Nava, que o doou ao Centro em outubro de 1978. Traz dedicatória de Austen Amaro para o memorialista, datada de Belo Horizonte, 2 de julho de 1926: "Há aqui alguma cousa da nossa sinceridade. Vão gostar muito dos teus desenhos; não é a minha admiração que te diz, é ainda a minha sinceridade". Na página em que está a dedicatória, Pedro Nava anotou: “obra rara". O colofão diz que "todos os exemplares vão de rubrica do autor", a qual se apõe a seguir. Na mesma página se lê "Pedro Nava desenhou". E mais abaixo há uma pequena errata: "O autor corrigiu neste livro trez erros que nas páginas 5, 17 e 38 aconteceram". Manuscrito a tinta, na mesma caligrafia da rubrica do autor, segue um acréscimo da errata: "E mais dois erros nas páginas 15 e 26". Nas cinco páginas referidas, encontram-se de fato emendas manuscritas do autor. O exemplar em questão ainda traz trechos e vocábulos sublinhados a lápis; essas marcas foram feitas por Pedro Nava, pois este era hábito seu e o tipo do lápis é o mesmo de marcas encontradas em outros livros de propriedade do escritor. Trata-se de um pequeno volume com 40 páginas, que tem como subtítulo na capa e na folha de rosto "poema lírico". Este se compõe de um dístico, um exlibris, uma introdução, seis cantos e um final.

Austen Amaro de Moura Drummond nasceu em 12 de dezembro de 1901 em Belo Horizonte, tendo feito carreira como funcionário público. $\mathrm{Na}$ década de 20 , conviveu com os modernistas mineiros e colaborou em A Revista, porta-voz do grupo de que participavam Carlos Drummond de Andrade, Abgar Renault, Pedro Nava, João Alphonsus, Emílio Moura, entre outros: No primeiro número de A Revista, de julho de 1925, Austen Amaro colaborou com um texto em prosa, "Irarigoan", pequeno relato de caráter

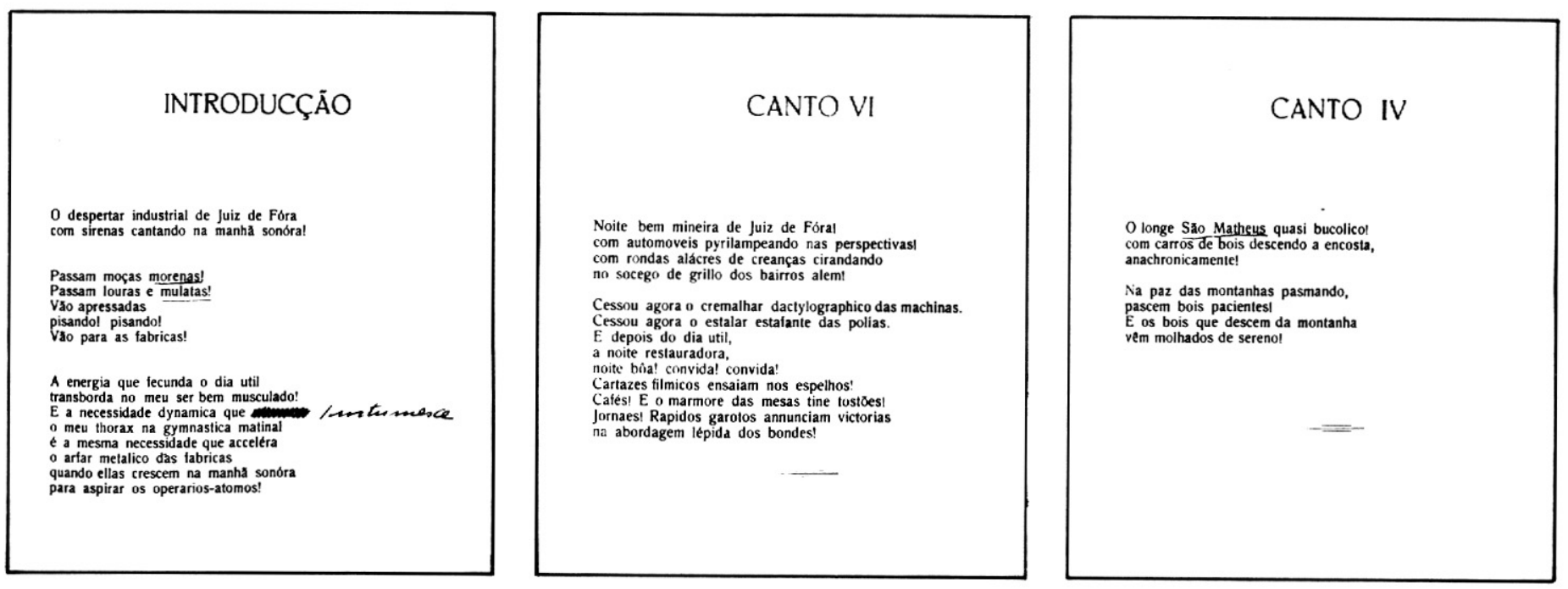

R E V I S S T A 
indianista. Em 1926, publicou Juiz de Fora-poema lírico. A seguir, publicou Ante o mistério do amor e da morte (1930), Poemetos à feição do oriente (1939), Imaginária Hélade (1971).

Vê-se, assim, que a produção de Austen Amaro teve continuidade após o livro inicial. Caberia então indagar a causa do esquecimento em que caiu Juiz de Fora. A indagação se faz especificamente em relação a esse livro, pois é ele que merece a recuperação. A mesma indagação já foi feita em relação a vários outros autores e certamente vez ou outra surgirá ocasião de se fazê-la de novo. As respostas são variadas, segundo os casos. Um autor terá interrompido sua produção, como ocorreu com Luiz Aranha ${ }^{(16)}$. Outro terá rompido muito violentamente com o padrão de sua época, como Sousândrade. Nenhum desses dois casos parece ser o de Austen Amaro, pois Juiz de Fora se insere no projeto modernista da época e não ficou como livro único. No caso de Austen Amaro, o motivo provavelmente se encontra em sua produção subseqüente. Nos livros seguintes a Juiz de Fora, o autor apresentou uma poesia de caráter místico e filosófico, com um vocabulário que se aproxima das escolhas simbolistas e com uma preocupação que recorre ao soneto e a curiosas elaborações como versos compostos de dois decassílabos ou dois dodecassílabos. Evidentemente, o interesse despertado por Juiz de Fora não foi sustentado pelos livros posteriores e acabou se desfazendo. Todavia, merece ser reativado o interesse por esse primeiro livro, merece ouvidos o diálogo de Juiz de Fora com a produção poética dos primeiros tempos do modernismo.

Manuel Bandeira falou, a propósito de Juiz de Fora, em uma "volta, em certos passos do poema, a certas formas e métricas românticas". Rosário Fusco, por sua vez, falou de "rastros parnasianos". É certo que uma e outra coisa podem ser vistas aqui e ali, como em algumas estrofes da "Introdução": "Tatouranas de pêlo eriçado/arrebentam-se à luz da fogueira,/espalhando no chão calcinado/o pus verde da tripa rasteira". Estas não são, porém, as marcas dominantes do livro. De fato preponderam marcas que situam Juiz de Fora dentro das perspectivas modernistas.

No plano vocabular, chama de imediato a atenção o uso abundante de criações neológicas a partir de várias formas de composição vocabular. Os exemplos se sucedem: ramerronam, aboriginando, arquitetizam, retrospectivam, elasticando, cosmopolitando, guturejante, foliginando, barbacenando, além de compostos como homem-peixe, casaspratibandas, sabre-punhal, operários-átomos. Esses neologismos não se constituem apenas em uma tentativa de novidade no nível léxico, mas assumem dimensão significativa mais ampla no conjunto de articulações do livro. Mas dois outros aspectos ainda se destacam no campo da seleção vocabular. De um lado, estão palavras ligadas ao âmbito do "primitivo", a uma paisagem brasileira, como braúna, taipa, arapapá, avencas, jenipapeiros, bananeiras, micos, tapera, jabuticabeira. De outro lado, encontram-se palavras ligadas à vida moderna, ao progresso, à industrialização, como sirenas, fábricas, operários, chaminés.

Se Juiz de Fora canta o progresso, a pujança, até com ufanismo, não perde de vista o aspecto mais "atrasado". As duas vertentes de seu vocabulário estão em consonância com sua tentativa de visão abrangente da realidade nacional. Se aqui e ali o texto resvala por um ufanismo duvidoso, em outros trechos há a compensação de uma admirável concisão com que se apreendem os aspectos mais simples do cenário brasileiro. A dimensão inovadora do vocabulário também vai ao encontro dessas duas direções, pois as criações vocabulares se apresentam como forma ou de captar a novidade e a velocidade do progresso, ou de introduzir como que eletricidade nos aspectos mais banais. Na poesia de Austen Amaro, a invenção vocabular na verdade estabelece uma ponte entre um Brasil do progresso e um Brasil bucólico; realiza-se no plano do vocabulário a integração meio mística da nacionalidade que é um dos sentidos do poema. Nesse âmbito, os cuidados do autor estendem-se ainda ao recurso constante às assonâncias ("foliginando fios fofos de fumaça!" ou "regatas retas remando"), a imagens e conceitos que chegam a ser proezas de síntese ("E ondas cobrejam nervos sobre o mar sensível" ou "O asfalto ressoa ao trepidar cosmopolita do capitalismo!") e a rico jogo de alternância de ritmos. Esses aspectos revelam especial preocupação com a construção do poema, construção que subjaz à aparência tumultuosa do poema.

Entre as várias associações que foram e podem ser lembradas em relação a Juiz de Fora impõe-se sem dúvida a de Mário de Andrade e seu "Noturno de Belo Horizonte". Mas essa associação se presta ainda a que se atente para algumas peculiaridades do texto de Austen Amaro. Também poema longo, Juiz de Fora, no entanto, se subdivide em diversas partes que subsistem como poemas isolados; alguns deles constituem mes-

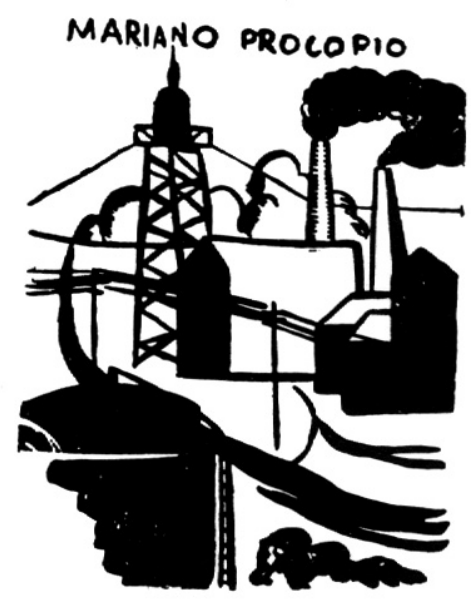

13 Id., ibid., p.195.

14 Verde. Ano 1, $n^{\circ} 4$, p. 10.

15 Beira-mar, Pedro Nava. p.221.

16 Cf. "Uma órbita excêntrica no modernismo", de Nelson Ascher, in Poemas, Luiz Aranha. Săo Paulo, Brasiliense, 1984. 
mo belos poemas curtos. A articulação de poemas autônomos num único poema longo é um dos resultados interessantes alcançados pelo poeta. Em relação ao poema de Mário de Andrade, o de Austen Amaro em seu percurso pela história e geografia do Brasil introduz personagens da história e da cultura de uma forma intensa, o que não é o caso no "Noturno". Em Juiz de Fora sucedem-se nomes fundamentais, até mesmo contemporâneos ao poema, trazendo para este questões então em plena efervescência, como neste trecho do Canto II:

Eu canto a promessa do Presente, com o Carlos Drummond e o João Alphonsus dos poemas brasileiros! com Villa-Lobos, e o Modesto Brocos da "Redempção de Cham"! E Tarsila do Amaral de hoje balbuciando a pintura brasílica! E Maria Lacerda de Moura! desejosa apenas de sinceridade!

Além de aproximações com outros autores, o poema de Austen Amaro sugere uma leitura que leve em conta algumas posições atuantes no modernismo. A questão dos contatos com o futurismo e dos equívocos (às vezes apenas de denominação) havidos à época já foi esclarecida. Mas em relação a Juiz de Fora podem ser lembrados alguns princípios futuristas expostos em manifestos. Com sua valorização do progresso, da máquina, da velocidade, o Manifesto do Futurismo diz: "1. Nós queremos cantar o amor ao perigo, o hábito à energia e à temeridade. 2. Os elementos essenciais de nossa poesia serão a coragem, a audácia e a revolta"(17). O ex-libris de Juiz de Fora, por sua vez, diz: "Eu canto a poesia da bigorna/com a rigidez enérgica do bíceps!" No Manifesto Técnico da Literatura Futurista, lê-se: "Nada é mais interessante, para um poeta futurista, que o agitar-se do teclado de um piano mecânico"(18). Em Juiz de Fora lêemse sucessivamente versos como "o arfar metálico das fábricas" ou "Cessou agora o cremalhar dactilográfico das máquinas". O mesmo Manifesto determina: "Cada substantivo deve ter o seu duplo, isto $\in$, o substantivo deve ser seguido, sem conjunção, do substantivo ao qual está ligado por analogia. Exemplo: homem-torpedeiro, mulher-golfo"(19) O vocabulário de Juiz de Fora tem exemplos suficientes dessa composição.

Essas aproximações se verificam em muitos textos da época. Mas quando Juiz de Fora se volta para a "Tapera distante!/de morros vazios! de morros macios!/com árvores pingando sombras pingues no mormaço!", o futurismo fica bem distante e o poema se insere numa discussão mais próxima. Essa discussão se estampava claramente em $A R e$ vista. No editorial do segundo número, verificava-se uma tentativa de acertar os ponteiros com a questão do regionalismo e do cosmopolitismo, em suma, com a questão de um "espírito nacional". Lê-se na revista:

"Acolhemos com simpatia o regionalismo. Aproveitamos nesse movimento alguns reflexos do nosso ambiente, a originalidade local do nosso interior. Se bem que pretendamos caminhar noutro sentido: dominar pelo espírito o nosso meio e não nos escravizarmos a ele. Mas é preciso superpormos vontades idênticas para criarmos um espírito nacional. (...) Não podemos desprezar a menor contribuição. Pressentimos o perigo enorme do cosmopolitismo. É a ameaça de dissolução do nosso espírito nas reações da transplantação exótica. (...) Aí está outro movimento nacionalista que traz também os seus frutos: o primitivismo"(20).

Juiz de Fora surgiu justamente em meio a essas questões. É mesmo possível dizer que o texto de Austen Amaro é em certo sentido uma formulação poética de preocupações modernistas. Austen Amaro conviveu com o grupo de A Revista e nela colaborou. Com seu poema enfrentou criativamente, ao lado de outros do grupo, as propostas que se manifestavam pelo periódico e que, por exemplo, ocupavam boa parte da correspondência de Mário de Andrade com Drummond. $O$ entusiasmo com o progresso e a ânsia de ser cosmopolita convivem no poema de Austen Amaro com a consciência poética da paisagem brasileira e da "vida besta" que nela transcorre. Mas Juiz de Fora merece sua recuperação não apenas por esses aspectos, que de resto o colocam ao lado de algumas das realizações importantes do período, mas também por seus momentos de especial inventividade e beleza. 